ESPAÇO TEMATICO: PROTEÇÃO SOCIAL NO CAPITALISMO CONTEMPORÂNEO:

CONTRARREFORMAS E REGRESSÕES DOS DIREITOS SOCIAIS

\title{
Estado Capitalista brasileiro: análise dos direitos sociais em tempos de ortodoxia neoliberal
}

\author{
Patrícia Soraya Mustafa ${ }^{1}$ \\ https://orcid.org/0000-0002-3668-1501 \\ ${ }^{1}$ Universidade Estadual Paulista "Júlio de Mesquita Filho", Departamento de Serviço Social, Franca, SP, Brasil
}

\section{Estado Capitalista brasileiro: análise dos direitos sociais em tempos de ortodoxia neoliberal}

Resumo: Este artigo, respaldado em uma pesquisa teórica e documental, tem o intuito de analisar o documento Uma Ponte para o Futuro, e para além dele, os feitos colocados em curso pelo atual governo (ilegítimo) do Movimento Democrático Brasileiro (MDB), como a contrarreforma trabalhista, as Emendas Constitucionais (EC) n ${ }^{\circ} 93$ e 95 e a proposta de contrarreforma da previdência social; elucidando seus impactos para a classe trabalhadora. Para realizar este estudo, partimos da compreensão de que o Estado capitalista está ontologicamente subordinado aos interesses do capital, e hoje, isso se expressa nas medidas adotadas e propostas pelo atual governo. Evidenciamos, ao final, após analisarmos o escopo da política econômica e social atual, quem vem sendo penalizado com essas medidas na sociedade brasileira.

Palavras-chave: Estado capitalista. Neoliberalismo. Uma Ponte para o Futuro. Ajuste fiscal. Direitos sociais.

\section{The Brazilian capitalist state: Analysis of social rights in times of neoliberal orthodoxy}

Abstract: This article is based on theoretical and documentary research and aims to analyze the document Uma Ponte para o Futuro [A bridge to the future], as well as the measures carried out by the (illegitimate) Brazilian government headed by the Brazilian Democratic Movement (MDB) in the period 2016-2018. Among the measures analyzed are the labor counterreform, the Constitutional Amendments (EC) 93 and 95, and the bill proposing a social security counterreform. The article emphasizes the impact of such measures on the working class. The study is based on the understanding of the capitalist state as ontologically subordinated to the interests of capital, which is expressed in the characteristics of the policies adopted and proposed by the MDB's government in Brazil. When analyzing the scope of the economic and social policy of the period, the article makes clear who is penalized with the measures put forward by the government.

Keywords: Capitalist state. Neoliberalism. Uma ponte para o futuro. Fiscal adjustment. Social rights.

Recebido em 18.05.2018. Aprovado em 18.09.2018. Revisado em 21.12.2018.

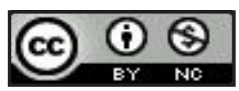

C O(s) Autor(es). 2019 Acesso Aberto Esta obra está licenciada sob os termos da Licença Creative Commons Atribuição-NãoComercial 4.0 Internacional (https://creativecommons.org/licenses/by-nc/4.0/deed.pt_BR), que permite copiar, distribuir e reproduzir em qualquer meio, bem como adaptar, transformar e criar a partir deste material, desde que para fins não comerciais e que você forneça o devido crédito aos autores e a fonte, insira um link para a Licença Creative Commons e indique se mudanças foram feitas. 


\section{Introdução}

Através de um estudo teórico, bibliográfico e documental, este artigo analisa a conjuntura econômica, política e social brasileira atual, partindo da premissa de que o Estado brasileiro, por se constituir num Estado capitalista, se orientará por proteger e promover os interesses do capital e seus representantes. Assim, não seria possível esperar de governos do Partido dos Trabalhadores (PT) e menos ainda do atual (não eleito), conduzido pelo Movimento Democrático Brasileiro (MDB) ${ }^{1}$, uma orientação diferente da dos representantes do poder econômico.

E certo que os governos do PT tentaram realizar uma conciliação de classes, porém o máximo que conseguiram foi angariar algumas conquistas ${ }^{2}$ para a classe trabalhadora, via aumento do salário mínimo, programas de transferência de renda, de moradia, de economia familiar, expansão de universidades públicas, política de crédito estudantil, dentre outros; e concomitantemente forneceram um banquete aos detentores do poder econômico via isenções tributárias, socorros financeiros aos bancos, pagamento dos juros e amortização dos títulos da dívida pública, dentre outros.

Já o atual governo do MDB, ainda que tente escamotear pelo discurso, joga no neoliberalismo radicalizado, do ajuste fiscal, da privatização, dos cortes sociais, nem que para isso tenha que sugar todo o sangue da classe trabalhadora, o que já estamos presenciando e evidenciaremos neste artigo.

Assim, neste texto, elucidaremos o que vem ocorrendo nestas terras sul-americanas após o golpe de 2016, que coloca na presidência um "político medíocre" (BOITO JUNIOR, 2016, p. 24) como Michel Temer, de um partido fisiologista, imerso na corrupção e comprometido com os interesses daqueles que detém o poderio econômico.

Analisaremos as principais medidas contidas no documento Uma Ponte para o Futuro elaborado pela Fundação Ulysses Guimarães e pelo Partido do Movimento Democrático Brasileiro (PMDB), no intuito de desocultá-las e problematizá-las, e delinearemos as reais intenções deste presidente que ora ocupa o poder político neste País.

Ademais, examinaremos algumas medidas já adotadas, ou que estão em vias de, como a contrarreforma trabalhista; a Emenda Constitucional (EC) n ${ }^{\circ}$ 93, do prolongamento da Desvinculação dos Recursos da União (DRU); a $\mathrm{EC} \mathrm{n}^{\circ} 95$, do congelamento dos gastos primários; a proposta de contrarreforma da previdência social; e mostraremos os impactos destas medidas, pesquisados até o momento (sem esgotá-los), já sentidos e que ainda serão sentidos, sobretudo pelos trabalhadores(as).

\section{Brasil, qual é a sua cara? O Estado brasileiro no atual contexto e as propostas do documento Uma Ponte para o Futuro}

Marx (2010, p. 22) já nos dizia que "O Estado é, essencialmente, uma expressão e um instrumento de reprodução dos interesses das classes dominantes [...]". Assim, entende-se que a sociabilidade capitalista produz um Estado capitalista, desta maneira, esta forma política Estado, enquanto a sociabilidade capitalista não for transplantada atenderá sempre ao seu senhor: o capital. Como elucida Mascaro (2015, p. 19), "[...] a classe burguesa estrutura uma sociedade burguesa não porque controla o Estado. O Estado poderia estar nas mãos de outros e, mesmo assim, a sociedade continuaria burguesa".

Deste modo, observamos que mesmo se a classe trabalhadora tiver o controle do Estado, ainda assim, para Marx (2011), a sociedade continuaria a mesma, só mudaríamos o seu administrador, pois sua estrutura é burguesa. Na obra $O 18$ de Brumário, Marx (2011) deixa claro que embora o Estado não esteja sendo administrado diretamente por um burguês, sua estrutura é burguesa.

Mascaro (2015) exemplifica: se um fazendeiro deixa sua fazenda ser administrada por um trabalhador, este o fará de acordo com os interesses do fazendeiro, uma vez que a fazenda não deixou de ser do fazendeiro! Logo, enquanto estivermos sob a égide do capital, o Estado não deixa de pertencer ao capital!

Isto explica porque em países em que a esquerda assume o poder do Estado, esta consegue somente, e em algumas circunstâncias, estabelecer reformas que favoreçam a classe trabalhadora, como foi o caso do Chile de Allende (Mascaro, 2015), e de alguns governos ${ }^{3}$ latino-americanos recentes. Entretanto, o que alcançam no máximo são alguns direitos a mais para a classe trabalhadora, direitos estes revogáveis em seguida, seja pelos golpes militares, parlamentares, midiáticos, juristas, empresariais, ou pelo retorno, via eleitoral, de partidos comprometidos com o neoliberalismo puro e radicalizado.

[...] Engels afirma que é possível lutar por direitos e conquistar alguns deles, mas isso é pontual [...]. O capital segue com o controle do poder, suas formas balizam a sociabilidade, a estrutura da exploração é 
capitalista, então, o que eventualmente se venha a ganhar na estrutura do bem-estar social reformista rapidamente se perde. (MASCARO, 2015, p. 23).

O que Marx (2013) deixa claro desde seu livro Crítica da filosofia do direito de Hegel - Introdução - é que o problema não está no Estado, mas na sociedade capitalista - sociedade de classes. Portanto, se o Estado representa alguma razão, como defendia Hegel, esta era a razão da burguesia, a qual defende que "cada um é cada um", e "todos somos iguais" (MASCARO, 2015, p. 16).

Trazidas estas referências basilares, passemos a analisar o atual contexto brasileiro, marcado por golpe parlamentar, empresarial, midiático e jurista; por crise econômica, política e institucional.

Primeiramente, e de acordo com as referências postas acima, cabe dizer que a crise brasileira será analisada pelo viés do conflito entre diferentes classes e frações de classe. A esse respeito, elucida Boito Junior (2016, p. 25): "O que temos aqui é um conflito distributivo, pela apropriação da riqueza, e ele envolve diversas classes e frações".

Além disso, envolve ainda diferentes partidos políticos e seus interesses, que representam interesses de classes, alguns deles travestidos pelo discurso da defesa da moralidade na política, sobretudo os que apoiaram a deposição da presidenta eleita Dilma Rousseff, com a justificativa de varrer a corrupção, enquanto tais partidos a têm escondida sob os seus próprios tapetes, como é possível se constatar na declaração de Romero Jucá em gravações que mostram claramente o envolvimento de muitos parlamentares que tentam a todo custo barrar a Operação Lava Jato.

Os governos do PT tentaram, durante todo o tempo em que estiveram no poder, conciliar os interesses de diferentes classes e suas frações, com o apoio, inclusive, de parte do empresariado, incluindo a Federação das Indústrias do Estado de São Paulo (FIESP), que mais tarde protagonizou as manifestações das classes que clamaram pelo impeachment, com clara intenção política e econômica, mobilizando "manifestantes fantoches"4 (PARAÍSO..., 2018), como bem acaba de retratar, de modo irônico e alegórico, no último carnaval (2018), a escola de samba carioca Paraíso do Tuiuti. Nesta tentativa conciliatória, também tiveram o apoio de movimentos sociais, sindicatos e de trabalhadores, para os quais concedeu alguns programas/políticas sociais, sem contudo abandonar a cartilha neoliberal.

A política de conciliação de classes, entretanto, falha e com ela aprendemos mais uma vez que: "A eleição promove a ilusão de que o conflito político se resolve num único dia e que, pelo mandato popular, se alcança algo, o 'poder', que, uma vez conquistado, permite que todos os problemas sejam solucionados". (MIGUEL, 2016, p. 35). Este mesmo autor realça que isto se constitui numa "armadilha da democracia limitada" (MIGUEL, 2016, p. 36), ou seja, como se as eleições pudessem direcionar toda a luta política. E isso é um equívoco!

Conforme Löwy (2016, p. 62), o que vem predominando nos últimos dois séculos é um "[...] Estado de exceção. [Pois, para este autor,] a democracia é que foi excepcional. De uma forma ou de outra, fica claro que ela é um

Mais uma vez evidencia-se quem, de fato, vem abocanhando os recursos públicos, e os motivos pelos quais os governos neoliberais a todo o momento dizem que não há recursos, que o Estado é muito oneroso, que é preciso apertar os cintos etc. Trata-se de um discurso falacioso que ilude e faz com que parte da classe trabalhadora, ludibriada também pela mídia, aceite este falatório como verdadeiro. peso grande para o Estado, para as classes dominantes e para o capital financeiro. A democracia atrapalha, ela não facilita o trabalho da política capitalista".

O golpe brasileiro evidencia notoriamente esta tendência apontada por Löwy (2016), visto que a política capitalista almeja buscar a acumulação e o aumento das taxas de lucro, mas, para isso, precisa manter e até aprofundar a exploração da classe trabalhadora, superexplorada ${ }^{5}$ no contexto brasileiro. Desse modo, para pôr em ação as políticas que atendem a estes interesses, entra em cena o "presidente vampiro" (PARAÍSO..., 2018), figura muito bem representada na Marquês de Sapucaí, pela escola de samba acima referida, vicecampeã do carnaval desse ano.

Neste contexto trágico-cômico, as propostas-chave deste "presidente vampiro" (PARAÍSO..., 2018) e seus correligionários estão no documento intitulado Uma Ponte para o Futuro, produzido pela Fundação Ulysses Guimarães e pelo PMDB. 
Ao se analisar o documento Uma Ponte para o Futuro, podemos observar claramente os recuos a saber:

Primeiramente, aponta que a crise fiscal do Estado é a grande responsável pelo não crescimento econômico. Culpa-se o Estado como se fosse o grande responsável pela crise, sobretudo o Estado Social, o qual no Brasil nem chega de fato a ser implementado. Assim, se justifica o plano de austeridade fiscal - para que o parco fundo público, antes destinado ao financiamento dos direitos sociais, seja, agora, canalizado para o pagamento da dívida pública ${ }^{6}$, favorecendo no Brasil, sobretudo, ao mercado financeiro.

Assim, é preciso buscar um "funcionamento virtuoso do Estado" (FUNDAÇÃO ULYSSES GUIMARÃES; PARTIDO DO MOVIMENTO DEMOCRÁTICO BRASILEIRO, 2015, p. 5), conforme determina este documento. Seguindo por este caminho, este mesmo documento propõe a desvinculação das receitas garantidas constitucionalmente, o que pressupõe alterar a Constituição Federal (CF) de 1988 em favor do que denominam "autonomia anual do orçamento" (FUNDAÇÃO ULYSSES GUIMARÃES; PARTIDO DO MOVIMENTO DEMOCRÁTICO BRASILEIRO, 2015, p. 9) e de "[...] orçamento com base zero" (FUNDAÇÃO ULYSSES GUIMARÃES; PARTIDO DO MOVIMENTO DEMOCRÁTICO BRASILEIRO, 2015, p. 10), conferindo ao Congresso o poder de definir anualmente quais os programas estatais continuam ou não.

Isso traz um sério problema para o campo dos direitos sociais, bem como para a Seguridade Social, cujas fontes de financiamento são garantidas no artigo 195 da CF de 1988. Tal prejuízo também se insere na esfera da educação, uma vez que também tem uma vinculação constitucional de financiamento.

Ademais, defendem o fim da indexação dos benefícios previdenciários e sociais ao salário mínimo, afirmando que o Parlamento é que deve arbitrar quais serão os reajustes a cada ano, de acordo com o crescimento da economia e disposição do orçamento (FUNDAÇÃO ULYSSES GUIMARÃES; PARTIDO DO MOVIMENTO DEMOCRÁTICO BRASILEIRO, 2015).

Porém, sabemos que, tanto a vinculação constitucional das receitas no campo dos direitos sociais, quanto à indexação de benefícios sociais ao salário mínimo foram fundamentais para que se pudesse sanar minimamente as iniquidades sociais perpetradas historicamente neste País, promovendo, por exemplo, a queda da pobreza entre os idosos e a equiparação dos benefícios entre trabalhadores do campo e da cidade. Entretanto, ainda assim, este "presidente vampiro" (PARAÍSO..., 2018) pretende sugar estes parcos avanços da classe trabalhadora brasileira.

E quem definiria este orçamento para o campo dos direitos sociais? O parlamento. Pasmem! O parlamento. Rapidamente, quem é o parlamento brasileiro, hoje? Löwy $(2016$, p. 65) já o definiu de modo notável: "[...] uma cambada de parlamentares reacionários e notoriamente corruptos [...]" composta sobretudo por partidos de direita que compõem "[...] a bancada BBB: da bala (deputados ligados à polícia militar, aos esquadrões da morte e às milícias privadas), do boi (grandes proprietários de terra, criadores de gado) e da Bíblia (neopentecostais integristas, homofóbicos e misóginos)".

Verifica-se, portanto, que tais parlamentares não representam os interesses da classe trabalhadora. Diante deste cenário nefasto, o que esperar? Como disse Leda Paulani (2016, p. 75): "uma agenda purosangue do neoliberalismo".

\section{A quem é tributado o ônus na sociedade brasileira? Análise das principais contrarreformas em curso}

Será conferido a FIESP? Aos grandes latifundiários? Aos bancos? Nas próximas linhas, pretende-se elucidar quem, de fato, arca com os ônus das principais contrarreformas. Várias são as medidas aprovadas, ou em curso de aprovação, que nos possibilitam responder à indagação anterior.

A contrarreforma trabalhista, por exemplo, ou "golpe trabalhista" (MAIOR, 2017b) já aprovado, e em vigor desde 16 de novembro de 2017, introduz a prevalência dos acordos coletivos em relação à lei em pontos específicos, propõe algumas garantias ao trabalhador terceirizado ${ }^{7}$ e o fim da obrigatoriedade da contribuição sindical, entre outros retrocessos. O documento cria ainda duas modalidades de contratação: a de trabalho intermitente, por jornada ou hora de serviço, e também o home office ${ }^{8}$ (MENDONÇA, 2017).

Assim, trabalhadores e empregadores, como se ambos tivessem a mesma força, devem entrar num pseudoacordo sobre o parcelamento de férias, pois anteriormente não se podia dividir as férias, exceto em alguns casos, em duas vezes. Quanto ao cumprimento da jornada de trabalho, antes de 44 horas semanais, oito horas diárias, agora ela pode chegar a 48 horas semanais, 12 horas diárias. Sobre a ida ao trabalho quando não há transporte público, anteriormente este tempo se contabilizava como tempo de trabalho, mas agora isto deve ser acordado. Além disso, houve alteração também sobre o intervalo durante a jornada de trabalho. Ou seja, dificilmente se conseguirá sustentar as garantias anteriormente conquistadas e garantidas por meio da lei. 
Como ressalta Souto Maior (2017a), esta legislação foi encomendada por um setor específico da sociedade e "[...] se almeja com essa lei destruir direitos trabalhistas, aniquilar as possibilidades de organização, de resistência e de reivindicação da classe trabalhadora e dificultar ao máximo o acesso à Justiça do Trabalho.” E ainda:

[...] reforma trabalhista não foi nada além do que o aproveitamento de uma oportunidade, dada pelas crises política e econômica, para possibilitar ao poder econômico aumentar sua taxa de lucro por meio de uma maior exploração do trabalho sem contrapartida social. (MAIOR, 2017b).

Cumpre ainda referenciar aqui outro golpe desferido à classe trabalhadora: a Portaria $\mathrm{n}^{\circ} 1.129$, de 20 de outubro de 2017, a qual tenta "[...] eliminar o conceito de trabalho em condições análogas às de escravo e inviabilizar a fiscalização estatal a respeito". (MAIOR, 2017a). Recorde-se a herança escravocrata brasileira e o quanto esta forma de trabalho marcou e marca ainda hoje a classe trabalhadora livre no Brasil. Portanto, esta portaria é uma afronta a todas as lutas sociais em prol de condições mais dignas de trabalho, além de um retrocesso desmedido para os(as) trabalhadores(as) brasileiros(as).

Quanto à contrarreforma da previdência social, o documento Uma Ponte para o Futuro anuncia a necessidade da reforma, sob as seguintes justificativas: déficit na seguridade social, envelhecimento populacional e o equilíbrio financeiro do sistema previdenciário (FUNDAÇÃO ULYSSES GUIMARÃES; PARTIDO DO MOVIMENTO DEMOCRÁTICO BRASILEIRO, 2015).

No entanto, como diz Fagnani (2016, p. 88): "Por trás dessa suposta reforma, oculta-se a mais feroz disputa por recursos públicos. O capital quer de volta os $10 \%$ do PIB da seguridade social. Essa disputa por recursos é uma das faces da luta de classes".

Marques e Ugino (2017) evidenciam as principais mudanças nas regras previdenciárias propostas no governo interino de Temer: idade mínima de 65 anos, para homem e mulher da área rural e urbana para fins de aposentadoria; 25 anos de contribuição para fins de aposentadoria, antes eram 15 anos, e mesmo tendo 25 anos de contribuição, o trabalhador receberá $70 \%$ do benefício, para cada ano trabalhado, a cada cinco anos a mais de contribuição há um percentual mínimo acrescido; além da adequação entre os regimes dos trabalhadores ligados ao Regime Geral de Previdência Social (RGPS) e dos servidores públicos da União, exceto aos das Forças Armadas; quanto à aposentadoria por invalidez, atualmente de valor integral do benefício, o novo valor seria de $51 \%$, com acréscimo de $1 \%$ para cada ano de trabalho.

Se esta contrarreforma for aprovada:

[...] no futuro, 47,3\% das mulheres não vão alcançar os 25 anos de contribuição. Para os homens, esse percentual será de $30 \%$. Então é claro que essa reforma vai afetar os homens também, porque muitos sofrem com o trabalho precário, com a rotatividade, mas vai afetar ainda mais as mulheres, justamente por conta da divisão sexual do trabalho. (MOSTAFA, 2017).

Não vamos polemizar neste texto a questão da divisão sexual do trabalho, mas impossível deixar de mencionar que as mulheres trabalham mais que os homens, em média oito horas a mais por semana (MOSTAFA, 2017), embora recebam menores salários, e por isso devem ter direito à aposentadoria antes deles.

Cabe também, em um átimo, reiterar, juntamente com Denise Gentil (2006), Associação Nacional dos Auditores Fiscais da Receita Federal do Brasil (ANFIP) (2016), e Fagnani (2015, 2016, 2017), que não há déficit na seguridade social: a seguridade social conta com um rol de contribuições, previstas pelo artigo 195 da CF, como já apontamos aqui, sendo a Contribuição Social Sobre o Lucro líquido (CSLL), a Contribuição Social para o Financiamento da Seguridade Social (COFINS), Contribuição Social do PIS/Pasep, a contribuição de empregados e empregadores para a seguridade social e os recursos dos concursos de prognósticos.

Sob a ótica de Fagnani $(2015,2016)$, nunca se cumpriu o que foi instituído em 1988 no que diz respeito ao financiamento, à organização e ao controle da seguridade social, embora o documento Uma Ponte para o Futuro e o governo que o leva a cabo, expressem isso, desconsiderando a previdência social como parte integrante da seguridade social. "Desde 1989, o MPAS [antigo Ministério da Previdência e Assistência Social] adota critério contábil segundo o qual a sustentação financeira da Previdência depende exclusivamente das receitas próprias do setor (empregados e empregadores).” (FAGNANI, 2015).

Já a ANFIP, na obra $A$ análise da Seguridade Social em 2016, confirma e prova que não há déficit na seguridade social brasileira, até 2015, mas sim superávit em média de 50.185 milhões de reais de 2005 a 2016 .

Quanto à pseudojustificativa do envelhecimento populacional no Brasil, a população em idade ativa ainda será a maioria em 2030 - mais de 60\%, segundo dados extraídos a partir de Borges, Campos e Silva (2015) - o que justifica denominarmos tal argumento de pseudojustificativa e a concluir que, com base na realidade brasileira, este é "[...] um argumento ideológico" (GRANEMANN, 2013, p. 153), e não real/concreto. 
Fagnani (2017), por sua vez, chama a atenção para este discurso ideologizado que tenta a todo custo nos convencer de que o envelhecimento populacional brasileiro pode ser comparado com o dos países europeus.

Outra medida no sentido de praticar a política de ajuste fiscal já foi promulgada em 15 de dezembro de 2016: a Emenda Constitucional (EC) ${ }^{\circ}$ 95, que congela os gastos sociais por 20 anos, sob o argumento de se economizar para que se pague a dívida pública e gere superávit primário. Entretanto, há que se dizer que o Brasil obteve déficit primário somente nos dois últimos anos da última década. "A obsessão alarmista contra qualquer elevação da dívida pública esconde uma agenda política a favor dos grupos financeiros e internacionais travestida como uma questão meramente técnica [...]" (AUSTERIDADE..., 2016, p. 22).

Aliás, já há estudos que comprovam o impacto desta EC n ${ }^{\circ} 95$ de 2016 no orçamento das políticas sociais. Para a Política de Assistência Social, o orçamento seria reduzido em 1,26\% do Produto Interno Bruto (PIB) de 2015 para 0,70\% em 2036 (PAIVA et al., 2016).

Há de se destacar que o orçamento desta política social apresentou um crescimento de 36 bilhões em 2006 para 74 bilhões em 2015, portanto, mais do que dobrou. Não cabe aqui uma análise do escopo desta política social, pois já fizemos estes apontamentos em outros ensaios.

Só na política da saúde, a perda de recurso destinado a essa área em 20 anos, por exemplo, será de aproximadamente R $\$ 654$ bilhões, se o PIB crescer 2\% ao ano (VIEIRA; BENEVIDES, 2016). A EC n ${ }^{\circ} 29$ estabelecia percentuais mínimos de contribuição para a saúde. Em 2015 a EC n ${ }^{\circ} 86$ altera tal medida, e vincula a aplicação mínima a um percentual da Receita Corrente Líquida (RCL), de forma escalonada $-13,2 \%$ da RCL em 2016; 13,7\% em 2017; 14,2\% em 2018; 14,7\% em 2019 e 15\% em 2020 - em ações e serviços públicos em saúde. A EC no 95 revoga esta EC no 86 (VIEIRA; BENEVIDES, 2016).

$\mathrm{Na}$ área da educação:

[...] consultores da Câmara estimaram em agosto que a área perderá 45 bilhões de reais até 2025 com o limite do aumento de gastos. O congelamento deve inviabilizar o cumprimento da meta de universalizar o atendimento das crianças e adolescentes até 2020, como prevê o Plano Nacional de Educação. (PEC..., 2016).

Além dessas novas medidas, há a permanência de uma velha/atualizada medida, a chamada Desvinculação dos Recursos da União (DRU), que com a EC n ${ }^{\circ} 93$ de 2016 editada ainda sob os auspícios da presidenta Dilma Rousseff, amplia de $20 \%$ para $30 \%$ o montante de recursos que pode ser desvinculado pela DRU, ademais ocorre uma alteração dos tributos que podem ser desvinculados, são eles: os fundos constitucionais, taxas e compensações financeiras (SALVADOR, 2017).

Salvador $(2010,2017)$ alerta-nos para o fato de que os superávits primários, entre 2000 e 2007, vêm sendo alcançados através dos efeitos deletérios da DRU nas receitas próprias da seguridade social, totalizando um percentual de $62,45 \%$ do superávit primário do governo federal: uma quantia, portanto, bastante significativa.

Salvador (2017) também revela como o orçamento da seguridade social vem sendo derruído devido à incidência da DRU e das renúncias tributarias, perfazendo um total de R $\$ 269,50$ bilhões em 2016, o que corresponde a "[...] 37,60\% acima dos recursos que foram destinados no mesmo ano para as políticas de saúde e assistência social no orçamento da União, que totalizaram o montante R\$ 195,86 bilhões [...]" (SALVADOR, 2017, p. 437).

Estes dados evidenciam um verdadeiro assalto à seguridade social brasileira, que desfinanciada, não efetiva a proteção social necessária à classe trabalhadora. Ademais, elucida como o fundo público é disputado por interesses divergentes, comprovando o caráter político do mesmo (SALVADOR, 2010, 2017).

Quanto às renúncias tributárias, estas aumentaram de $\mathrm{R} \$ 217,27$ bilhões (2010) para $\mathrm{R} \$ 319,23$ bilhões (2016), perfazendo um incremento de 46,93\% acima da inflação (SALVADOR, 2017). Se compararmos com o aumento do orçamento da seguridade social, na mesma variação de anos, vemos que este é de somente $28,28 \%$ (Salvador, 2017). No cômputo total, as renúncias tributárias neste mesmo período "[...] implicaram uma perda de arrecadação equivalente a $20,68 \%$ das receitas do governo federal ou $4,33 \%$ do PIB”. (SALVADOR, 2017, p. 439).

Mais uma vez evidencia-se quem, de fato, vem abocanhando os recursos públicos, e os motivos pelos quais os governos neoliberais a todo o momento dizem que não há recursos, que o Estado é muito oneroso, que é preciso apertar os cintos etc. Trata-se de um discurso falacioso que ilude e faz com que parte da classe trabalhadora, ludibriada também pela mídia, aceite este falatório como verdadeiro.

Nesse contexto, compete a nós, intelectuais, entre outros fatores,

[...] desconstruir evidências (pelo desvelamento dos mecanismos ideológicos que a produzem), implodir a unanimidade (pela exposição das fissuras existentes em construções que se pretendem sólidas e apelar à mudança (que, no fundo, é apelar ao exercício da liberdade humana). (BENJAMIN, 2000, p. 6). 
Sob esta perspectiva, é preciso evidenciar também que apesar da crise, o segundo maior banco privado do Brasil, o Bradesco, teve seu lucro líquido em alta de 7,8\% no terceiro trimestre de 2017, para R\$ 4,8 bilhões, na comparação com mesmo período de 2016, em relação ao segundo trimestre de 2017, alta de $2,3 \%$. Ora, em um momento de crise disseminada, como um banco pode obter essa colossal alta de lucro? (FERNANDES, 2017).

Em contrapartida, qual foi o aumento do salário mínimo para este ano? Pífios 1,81\%, 2,07\% abaixo do Índice Nacional de Preços ao Consumidor (INPC), alerta Sá Neto (2018), além de inconstitucional, foi o menor reajuste em 24 anos de luta por melhorias salariais.

Diante deste cenário, a desigualdade social volta a aumentar no Brasil, de acordo com o diagnóstico do Programa das Nações Unidas para o Desenvolvimento (PNUD), em 2017 o Brasil era o $10^{\circ}$ país mais desigual do mundo e o quarto da América Latina, à frente apenas de Haiti, Colômbia e Paraguai, segundo o Coeficiente de Gini, que mede a concentração renda, e o percentual de desigualdade de renda no Brasil (37\%) é superior à média da América Latina, incluindo os países do Caribe (34,9\%) (PIRES, 2017).

Por fim, a Pesquisa Nacional por Amostras de Domicílios (PNAD), divulgada pelo Instituto Brasileiro de Geografia e Estatística (IBGE), no dia 23 de fevereiro de 2018, mostra dados referentes ao quarto trimestre de 2017, revelando que o Brasil fechou 2017 com 26,4 milhões de subempregados ${ }^{9}$ (EM..., 2018). A taxa de subutilização no quarto trimestre foi de 23,6\% (EM..., 2018). E a taxa média de desemprego em 2017 foi de 12,7\%, maior do que em 2016 (11,5\%), a maior da série histórica da pesquisa (BÔAS, 2018).

Dessa maneira, parece-nos axiomático que a classe trabalhadora é quem paga o pato na sociedade brasileira, ao contrário do que propalou a FIESP e seus apoiadores.

\section{Considerações Finais}

Nas linhas acima, partindo da premissa de que numa organização social capitalista não se pode ter a ilusão de que o Estado não seja capitalista, evidenciamos como o Estado capitalista brasileiro vem defendendo atualmente os interesses daqueles que detêm o poder econômico.

Procuramos demonstrar que embora os governos anteriores, do PT, tenham tentado conduzir uma política de conciliação de classes, e em algum momento e medida isto foi relativamente possível, ao fim e ao cabo o banquete não foi servido para os trabalhadores, mas apenas ao capital, que ainda não fartos com o mesmo, exigiram mais, o que culminou na deposição deste partido político do poder, e, por conseguinte, inicia-se, a partir de então, a era do neoliberalismo "puro-sangue" (PAULANI, 2016, p. 75), dirigido pelo MDB e seus comparsas.

Assim, elucidamos, ao longo desse ensaio, as principais propostas deste partido, prescritas no documento Uma Ponte para o Futuro, algumas delas já implementadas e outras em vias de aprovação.

Dentre estas medidas, destacamos a contrarreforma trabalhista, muito bem definida por Maior (2017b) como "golpe trabalhista", que indica claramente prejuízos à classe trabalhadora quanto à jornada de trabalho, ao tipo de contrato estabelecido, ao acesso à justiça trabalhista, dentre outros; a promulgação da $\mathrm{EC} \mathrm{n}^{\circ} 93$ que prorroga e alarga os desvios do orçamento da União, favorecendo, ainda mais, a retirada de recursos dos direitos sociais para amortização e pagamento dos juros da dívida pública; a EC $\mathrm{n}^{\circ} 95$, aqui, evidenciamos algumas projeções de seu impacto nefasto no financiamento de algumas políticas sociais; e a contrarreforma da previdência social, que se aprovada sentenciará os(as) trabalhadores(as) ao trabalho precário, alienante, alienador, superexplorado e perpétuo.

Desse modo, a classe trabalhadora, cada vez mais, terá dificuldades para satisfazer suas necessidades mais elementares, numa sociabilidade que cria e recria a cada dia novas necessidades, de modo que o trabalhador estará cada vez mais preso aos grilhões do trabalho em busca da comida, da morada, isto é, preso ao mundo das necessidades. E, como nos recorda Fontes (2017, p. 410): "A liberdade é o uso do tempo para além da necessidade, quando as necessidades fundamentais estão supridas".

Assim, como usufruir da liberdade numa sociabilidade que nos prende cada vez mais às necessidades?

$\mathrm{Se}$, por um curto período, alguns direitos sociais e trabalhistas permitiram amenizar as necessidades mais prementes, agora, com a destruição destes, cada vez mais a vida se converterá em "[...] tempo da venda de força de trabalho". (FONTES, 2017, p. 410).

Contudo, como resistir diante deste cenário, em que "[...] o papel civilizador do capitalismo se atrofia e se converte no seu antípoda, a barbarização da vida social [...] [?]” (PAULO NETTO, 2017).

Diria que os intelectuais tem um papel fundamental neste cenário, o da crítica: crítica ao modo de produzir sob o capital, crítica, portanto, ao trabalho no capitalismo. Mas esta crítica deve ser uma crítica ontológica, dirigida "[...] aos pressupostos estruturais da tradição criticada. [...] tem de ser crítica que refigura o mundo, que põe e pressupõe outra ontologia". (DUAYER, 2015, p. 124). 
E esta tarefa não é fácil, é desafiadora porque pressupõe que "[...] teremos de enfrentar questões realmente difíceis - questões não sobre aquilo que não queremos, mas sobre aquilo que queremos". (ŽIŽEK2011).

Assim, a esquerda, hoje, precisa reconstruir esta crítica ontológica, e ir para além dos protestos contra a falência do Estado Social, ainda que não desconsideremos a importância destes. A questão fundamental, assim, é "[...] saber como reconstruir as coordenadas ideológicas contra-hegemônicas, nas quais a ideia de revolução e transformação substantiva e radical da sociedade possa ter sentido, fazer sentido". (DUAYER, 2015, p. 120).

\section{Referências}

AMARAL, M. Jabuti não sobe em árvore: como o MBL se tornou líder das manifestações pelo impeachment. In: JINKINGS, I.; DORIA, K.; CLETO, M. (org.). Por que gritamos golpe?: para entender o impeachment e a crise política no Brasil. São Paulo: Boitempo, 2016. p. 49-54.

ASSOCIAÇÃO NACIONAL DOS AUDITORES FISCAIS DA RECEITA FEDERAL DO BRASIL. Análise da seguridade social 2016. Brasília, DF: ANFIP, 2016.

AUSTERIDADE e retrocesso: finanças públicas e política fiscal no Brasil. São Paulo: Fórum 21, 2016. Disponível em: http:// brasildebate.com.br/wp-content/uploads/Austeridade-e-Retrocesso.pdf. Acesso em: 20 out. 2016.

BENJAMIN, C. de Q. Introdução. In: BENJAMIN, C. de Q.; ELIAS, L. A. (org.). Brasil: crise e destino - entrevistas com pensadores contemporâneos. São Paulo: Expressão Popular, 2000. p. 05-12.

BÔAS, B. V. IBGE: Desemprego fica em 11,8\% no trimestre e em 12,7\% na media de 2017. Valor Econômico, São Paulo, 31 jan. 2018. Disponível em: http://www.valor.com.br/brasil/5295091/ibgedesemprego-fica-em-118-no-trimestre-e-em-127-na-media-de-2017. Acesso em: 1 fev. 2018.

BOITO JUNIOR, A. Os atores e o enredo da crise política. In: JINKINGS, I.; DORIA, K.; CLETO, M. (org.). Por que gritamos golpe?: para entender o impeachment e a crise política no Brasil. São Paulo: Boitempo, 2016. p. 23-30.

BORGES, G. M.; CAMPOS, M. B. de; SILVA, L. G. de C e. Transição da estrutura etária no Brasil: oportunidades e desafios para a sociedade nas próximas décadas. In: ERVATTI, L. R.; BORGES, G. M.; JARDIM, A. de P. (org.). Mudança demográfica no Brasil no início do século XXI: subsídios para as projeções da população. Rio de Janeiro: Instituto Brasileiro de Geografia e Estatística, 2015. p. 138-151. (Estudos e Análises. Informação Demográfica e Socioeconômica, 3).

BRASIL. [Constituição (1988)]. Constituição da República Federativa do Brasil. Diário Oficial [da] República Federal do Brasil, Brasília, DF, 5 out. 1988. Disponível em: http://www.planalto.gov.br/ccivil_03/constituicao/constituicao.htm. Acesso em: 10 fev. 2018. BRASIL. [Constituição (1988)]. Emenda constitucional n 29, de 13 de setembro de 2000. Altera os arts. 34, 35, 156, 160, 167 e 198 da Constituição Federal e acrescenta artigo ao Ato das Disposições Constitucionais Transitórias, para assegurar os recursos mínimos para o financiamento das ações e serviços públicos de saúde. Diário Oficial [da] República Federal do Brasil, Brasília, DF, 14 set. 2000. Disponível em: http://www.planalto.gov.br/ccivil_03/constituicao/Emendas/Emc/emc29.htm. Acesso em: 15 abr. 2017.

BRASIL. [Constituição (1988)]. Emenda constitucional nº 86, de 17 de março de 2015. Altera os arts. 165, 166 e 198 da Constituição Federal, para tornar obrigatória a execução da programação orçamentária que especifica. Diário Oficial da União, Brasília, DF, 18 mar. 2015. Disponível em: http://www.planalto.gov.br/ccivil_03/Constituicao/Emendas/Emc/emc86.htm. Acesso em: 15 de abr. de 2017.

BRASIL. [Constituição (1988)]. Emenda constitucional nº 93, de 08 de setembro de 2016. Altera o Ato das Disposições Constitucionais Transitórias para prorrogar a desvinculação de receitas da União e estabelecer a desvinculação de receitas dos Estados, Distrito Federal e Municípios. Diário Oficial da União, Brasília, DF, 9 set. 2016a. Disponível em: http://www.planalto.gov.br/ccivil_03/Constituicao/ Emendas/Emc/emc93.htm. Acesso em: 15 abr. 2017.

BRASIL. [Constituição (1988)]. Emenda constitucional n 95, de 15 de dezembro de 2016. Altera o Ato das Disposições Constitucionais Transitórias, para instituir o Novo Regime Fiscal, e dá outras providências. Diário Oficial da União, Brasília, DF, dez. 16 dez. $2016 b$. Disponível em: http://www.planalto.gov.br/ccivil_03/constituicao/emendas/emc/emc95.htm. Acesso em: 15 abr. 2017.

DUAYER, M. Crítica ontológica em Marx. In: PAULO NETTO, J. (org.). Curso livre Marx-Engels: a criação destruidora. São Paulo: Boitempo, 2015. p. 115-137.

EM cinco anos, dobra o número de pessoas que desistem de procurar emprego. Folha de S. Paulo, São Paulo, 23 fev. 2018. Disponível em: https:/www1.folha.uol.com.br/mercado/2018/02/brasil-termina-2017-com-265-milhoes-de-subempregados.shtml. Acesso em: 23 fev. 2018. FAGNANI, E. A previdência social não tem déficit. Revista Política Social e Desenvolvimento, ano 3, n. 28, p. 14-21. dez. 2015. Disponível em: http://plataformapoliticasocial.com.br/wp-content/uploads/2016/02/Revista_28.pdf. Acesso em: 10 nov. 2016.

FAGNANI, E. A reforma tributária e o último suspiro da proteção social. Carta Capital, São Paulo, 11 out. 2017. Disponível em: http:/ /www.ihu.unisinos.br/186-noticias/noticias-2017/572563-a-reforma-tributaria-e-o-ultimo-suspiro-da-protecao-social. Acesso em: 15 out. 2017.

FAGNANI, E. Previdência social: reformar ou destruir? In: JINKINGS, I.; DORIA, K.; CLETO, M. (org.). Por que gritamos golpe?: para entender o impeachment e a crise política no Brasil. São Paulo: Boitempo, 2016. p. 85-92.

FERNANDES, A. Lucro do Bradesco sobe 7,8\% no terceiro trimestre. Folha de S. Paulo, São Paulo, 1 nov. 2017. Disponível em: http:/ /www1.folha.uol.com.br/mercado/2017/11/1932093-lucro-do-bradesco-sobe-78-no-terceiro-trimestre.shtml. Acesso em: 1 nov. 2017. 
FONTES, V. Capitalismo, crises e conjuntura. Serviço Social \& Sociedade, São Paulo, n. 130, p. 409-425, set./dez. 2017.

FUNDAÇÃO ULYSSES GUIMARÃES; PARTIDO DO MOVIMENTO DEMOCRÁTICO BRASILEIRO. Uma Ponte para o Futuro. Brasília: Fundação Ulysses Guimaraes, 29 out. 2015. Disponível em: https://www.fundacaoulysses.org.br/wp-content/uploads/ 2016/11/UMA-PONTE-PARA-O-FUTURO.pdf. Acesso em: 10 nov. 2016.

GENTIL, D. Política fiscal e falsa crise da seguridade social brasileira: análise financeira do período 1990-2005. 2006. Dissertação (Tese em Economia) - Instituto de Economia, Universidade Federal do Rio de Janeiro, Rio de Janeiro, 2006.

GRANEMANN, S. Segurança social: fundo universal de solidariedade ou mercado privado de capitais? In: VARELA, R. (coord.). A segurança social é sustentável: trabalho, Estado e segurança social em Portugal. Lisboa: Bertrand, 2013. p. 150-170.

LÖWY, M. Da tragédia à farsa: o golpe de 2016 no Brasil. In: JINKINGS, I.; DORIA, K.; CLETO, M. (org.). Por que gritamos golpe?: Para entender o impeachment e a crise política no Brasil. São Paulo: Boitempo, 2016. p. 61-68.

MAIOR, J. L. S. A “reforma" trabalhista era para retirar direitos, reconhecem os "donos da bola”. Jorge Luiz Souto Maior, São Paulo, 22 out. 2017a. Disponível em: https://www.jorgesoutomaior.com/blog/a-reforma-trabalhista-era-para-retirar-direitos-reconhecem-osdonos-da-bola. Acesso em: 2 nov. 2017.

MAIOR, J. L. S. Impactos do golpe trabalhista (a Lei n. 13.467/17). Jorge Luiz Souto Maior, São Paulo, 29 ago. 2017b. Disponível em: https://www.jorgesoutomaior.com/blog/impactos-do-golpe-trabalhista-a-lei-n-1346717. Acesso em: 2 set. 2017.

MARQUES, R. M.; UGINO, C. K. Governo Temer: reflexões sobre a proposta de reforma da previdência. Plataforma Política Social, 2 jan. 2017. Disponível em: http://plataformapoliticasocial.com.br/governo-temer-reflexoes-sobre-a-proposta-de-reforma-da-previdencia/. Acesso em: 10 dez. 2017.

MARX, K. As glosas críticas marginais ao artigo: “O rei da Prússia e a Reforma Social”. São Paulo: Boitempo, 2010.

MARX, K. Crítica da filosofia do direito de Hegel. São Paulo: Boitempo, 2013.

MARX, K. O 18 de Brumário de Luís Bonaparte. São Paulo: Boitempo, 2011.

MASCARO, A. L. A crítica do Estado e do direito: a forma política e a forma jurídica. In: PAULO NETTO, J. (org.). Curso livre MarxEngels: a criação destruidora. São Paulo: Boitempo, 2015. p. 11-30.

MENDONÇA, H. Reforma trabalhista: saiba o que pode mudar. El País, São Paulo, 10 nov. 2017. Disponível em: http://brasil.elpais.com/ brasil/2017/04/25/politica/1493074533_442768.html. Acesso em: 25 abr. 2017.

MIGUEL, L. F. A democracia na encruzilhada. In: JINKINGS, I.; DORIA, K.; CLETO, M. (org.). Por que gritamos golpe?: Para entender o impeachment e a crise política no Brasil. São Paulo: Boitempo, 2016. p. 31-38.

MOSTAFA, J. "É uma reforma da Previdência muito perversa com as mulheres”. Entrevista. Carta Capital, São Paulo, 15 mar. 2017. Disponível em: https://www.cartacapital.com.br/economia/e-uma-reforma-da-previdencia-muito-perversa-com-as-mulheres. Acesso em: 15 mar. 2017.

OLIVEIRA, F. O surgimento do antivalor: capital, força de trabalho e fundo público. Novos Estudos Cebrap, São Paulo, n. 22, p. 8-28, out. 1988.

PAIVA, A. B. de et al. Nota técnica $n^{\circ}$ 27: O novo regime fiscal e suas implicações para a política de assistência social no Brasil. Brasília, DF: Instituto de Pesquisa Econômica Aplicada, set. 2016.

PARAÍSO do Tuiuti faz desfile histórico e eterniza o golpe na Sapucaí. Fórum, Santos, 12 fev. 2018. Disponível em: https:// www.revistaforum.com.br/paraiso-do-tuiuti-faz-desfile-historico-e-eterniza-o-golpe-na-sapucai2. Acesso em: 16 fev. 2018.

PAULANI, L. M. Uma ponte para o abismo. In: JINKINGS, I.; DORIA, K.; CLETO, M. (org.). Por que gritamos golpe?: Para entender o impeachment e a crise política no Brasil. São Paulo: Boitempo, 2016. p. 69-76.

PAULO NETTO, J. "O Capital não é uma bíblia nem um receituário", diz José Paulo Netto. [Entrevista cedida a] Juliana Gonçalves. Brasil de Fato, São Paulo, 16 set. 2017. Disponível em: https://www.brasildefato.com.br/2017/09/16/o-capital-nao-e-uma-biblia-nemum-receituario-diz-jose-paulo-netto. Acesso em: 18 set. 2017.

PEC 55, que congela gastos sociais, é aprovada em $2^{\circ}$ turno no Senado. Carta Capital, São Paulo, 13 dez. 2016. Disponível em: https:/ /www.cartacapital.com.br/politica/pec-que-congela-gastos-sociais-e-aprovada-em-segundo-turno-no-senado. Acesso em: 14 dez. 2016. PIRES, B. Brasil despenca 19 posições em ranking de desigualdade social da ONU. El País, São Paulo, 21 mar. 2017. Disponível em: https://brasil.elpais.com/brasil/2017/03/21/politica/1490112229_963711.html. Acesso em: 22 mar. 2017.

SALVADOR, E. Fundo público e seguridade social no Brasil. São Paulo: Cortez, 2010.

SALVADOR, E. O desmonte do financiamento da seguridade social em contexto de ajuste fiscal. Serviço Social \& Sociedade, São Paulo, n. 130, p. 426-446, set./dez. 2017. Disponível em: http://www.scielo.br/pdf/sssoc/n130/0101-6628-sssoc-130-0426.pdf. Acesso em: 20 jan. 2018.

SÁ NETO, F. M. A ladainha do "rombo da previdência". ANFIP, Brasília, DF, 25 jan. 2018. Disponível em: https://www.anfip.org.br/ noticia.php?id_noticia=22849. Acesso em: 23 fev. 2018.

VIEIRA, F. S.; BENEVIDES, R. P. S. Nota técnica $n^{\circ} 28$ : Os impactos do novo regime fiscal para o financiamento do Sistema Único de Saúde e para a efetivação do direito à saúde no Brasil. Brasília, DF: Instituto de Pesquisa Econômica Aplicada, set. 2016.

ŽIŽEK,S. A tinta vermelha: discurso de ŽiŽekno Occupy Wall Street. Blog da Boitempo, São Paulo, 11 out. 2011. Disponível em: https://blogdaboitempo.com.br/2011/10/11/a-tinta-vermelha-discurso-de-slavoj-zizek-aos-manifestantes-do-movimento-occupy-wallstreet/. Acesso em: 20 out. 2011. 


\section{Notas}

1 Numa tentativa de ludibriar a sociedade brasileira, o PMDB, envolto em fisiologismos, corrupção, muda de nome, voltando a utilizar a sigla MDB, legenda que se contrapôs ao regime militar no Brasil.

2 Não estamos desprezando as medidas sociais implementadas, ao contrário, as reconhecemos, apenas apontamos que ainda ficam com a menor parte do fundo público, o que significa que a classe trabalhadora, demandatária e financiadora destes direitos, não é a mais beneficiada nesta política conciliatória.

3 Uns numa perspectiva social-liberal, como o Chile, Uruguai e o próprio Brasil; outros, numa perspectiva "antineoliberal", "anti-imperialista" como Venezuela, Bolívia e Equador; e ainda aqueles que ficam “no meio do caminho”, como a Argentina, Paraguai, Nicarágua e El Salvador (LÖWY, 2016, p. 62).

4 Destacamos também a presença do Movimento Brasil Livre (MBL) sob o patrocínio dos norte-americanos: vide Amaral (2016).

5 Francisco de Oliveira (1988) diz que a superexploração do trabalho ocorre devido aos seguintes fatores: salários reduzidos, aumento da jornada de trabalho, trabalho sem contrato e maior intensidade do processo de trabalho.

6 Isso já vinha sendo praticado nos governos anteriores; entretanto, com este "presidente vampiro" (PARAÍSO..., 2018), está havendo um desfinanciamento ainda maior dos direitos sociais em prol do superávit primário, algo evidenciado no decorrer deste texto.

7 Lembrando que em 23 de março de 2017 aprovou-se a legislação que permite a terceirização irrestrita, e em que pese aos respectivos estudos demonstra-se o quanto o trabalho terceirizado é precário, seja porque os trabalhadores trabalham mais, seja porque ganham menos, seja porque ficam completamente desprotegidos de direitos trabalhistas.

8 Não trataremos aqui sobre as consequências do trabalho intermitente e o home office para os trabalhadores, mas apenas enfatizamos que o propósito destas modalidades é dar prosseguimento à superexploração da classe trabalhadora brasileira.

9 A taxa de subutilização do trabalho, segundo o IBGE, considera os desocupados, subocupados que trabalham menos de 40 horas semanais e os que fazem parte da força de trabalho potencial.

\section{Patrícia Soraya Mustafa}

patimustafa@gmail.com

Doutorado em Serviço Social pela Universidade Estadual Paulista “Júlio de Mesquita Filho" (UNESP)

Professora do Departamento de Serviço Social da Faculdade de Ciências Humanas e Sociais da Universidade Estadual Paulista "Júlio de Mesquita Filho" (UNESP)

\section{UNESP}

Av. Eufrásia Monteiro Petráglia, 900 - Jd. Dr. Antônio Petráglia

Franca - São Paulo - Brasil

CEP: $14.409-160$

\section{Agência financiadora \\ Não se aplica.}

\section{Contribuições dos autores}

Não se aplica.

\author{
Consentimento para publicação \\ Não se aplica.
}

\section{Conflito de interesses}

Não há conflito de interesses.

Aprovação por Comitê de Ética e consentimento para parti-

cipação

Não se aplica. 